\title{
Computer-Assisted Navigation in High Tibial Osteotomy: A Systematic Review of the Literature
}

\author{
Natasha E. Picardo ${ }^{*}$, , Wasim Khan ${ }^{2}$ and David Johnstone ${ }^{3}$ \\ ${ }^{I}$ Bone Tumour Unit, Royal National Orthopaedic Hospital, Stanmore, Middlesex, HA7 4LP, UK \\ ${ }^{2}$ University College London Institute of Orthopaedics and Musculoskeletal Sciences, Royal National Orthopaedic \\ Hospital, Stanmore, Middlesex, HA7 4LP, UK \\ ${ }^{3}$ Stoke Manderville Hospital, Aylesbury, Buckinghamshire, HP21 8AL, UK
}

\begin{abstract}
High tibial osteotomy (HTO) is a procedure which aims to change the mechanical axis of the lower limb, transferring the body weight across healthy articular cartilage. Several studies have shown that accurate correction is the leading predictor for success.

In this article, we systematically review the computer-assisted techniques that have been used in attempts to increase the accuracy of the surgery and improve postoperative outcomes. The results of the cadaveric and clinical studies to date are presented and the benefits and pitfalls of navigation are discussed.
\end{abstract}

Keywords: Computer-assisted surgery, high tibial osteotomy, kinematic navigation system, knee, mechanical axis, medial gonarthrosis, navigation, varus deformity.

\section{INTRODUCTION}

High tibial osteotomy (HTO) was first introduced in 1958 by Jackson [1]. It is a well-known treatment option for unicompartmental osteoarthritis of the knee with varus malalignment, particularly in young, active patients (less than 65 years of age with moderate arthritis), where total knee replacement is not advisable [2-4]. HTO is a realignment procedure which redistributes weight-bearing load from the diseased medial compartment to the relatively unaffected lateral compartment of the knee. This can alleviate symptoms and slow disease progression, thereby deferring subsequent total knee arthroplasty. Furthermore fibrocartilaginous proliferation is seen to occur in the diseased compartment, providing some evidence of biologic healing [5].

Popular techniques include medial opening wedge HTO with or without interposition of bone graft, lateral closed wedge technique and dome osteotomy. Many surgeons prefer the medial opening wedge technique as it is less invasive, involving a single transverse osteotomy and thereby avoiding damage to the lateral part of the knee, including the fibula and common peroneal nerve [6, 7]. There is no loss of osseous substance and it allows adjustment to be made in the sagittal and coronal planes [3].

Many fixation techniques have been described including external fixation with progressive distraction and a variety of internal fixation devices [8,9]. Proximal tibial osteotomies are regarded as technically demanding procedures with a steep learning curve. They provide the best results when they

\footnotetext{
*Address correspondence to this author at the Bone Tumour Unit, Royal National Orthopaedic Hospital, Stanmore, Middlesex, HA7 4LP, UK; Tel: 0208909 5532; Fax: 0208909 5100;

E-mail: emmapicardo@yahoo.co.uk
}

are well indicated and when the lower limb is accurately aligned.

\section{The Ideal Alignment}

Different recommendations are found in the literature, regarding the amount of correction that should be achieved postoperatively and no clear guidelines exist [10]. Most studies have found that slight overcorrection of valgus is essential to achieve longevity and avoid varus deformity recurrence [11]. Some authors refer to the anatomical axis of the tibia and femur and recommend a postoperative alignment of $8-10^{\circ}$ valgus [12-14]. Other authors concentrate on the mechanical alignment and recommend that this should be moved to $3-6^{\circ}$ of mechanical valgus, noting that results deteriorate outside this range $[3,15]$. When the mechanical axis passes through the centre of the knee, the medial compartment bears $67 \%$ of the load during single leg stance and when the mechanical axis is moved to $6^{\circ}$ of valgus, the load is $40 \%$ medial and $60 \%$ lateral [16]. Overcorrection to valgus is therefore necessary to unload the medial compartment.

In 1979, Fujisawa et al. [2] published results of a retrospective arthroscopic analysis of 54 patients performed after closing wedge HTO. The medial and lateral edges of the medial and lateral plateaus were considered to be $100 \%$ and the centre of the knee was $0 \%$. Best results were achieved when the mechanical axis passed through the lateral $30-40 \%$ of the tibial plateau as measured from its midpoint. This region has become known as the Fujisawa point. This area corresponds roughly to recommendations by Miniaci [17] and Noyes [18] who recommended that the weightbearing line should pass through a point at $60-70 \%$ of the tibial plateau width, as measured from the medial cortex. Years later, Jakob and Murphy modified the Fujisawa point, based on the degree of medial articular damage [19]. If the 
medial compartment degeneration is minimal, the goal is correction through the medial third (one third of the distance to Fujisawa's point). With severe arthrosis of the medial compartment, the mechanical axis is shifted to pass through Fujisawa's point.

\section{Problems with Conventional HTO}

In the long-term, the outcomes of HTO strongly depend on the achievement of desired correction, yet conventional HTO techniques have demonstrated high variability [3]. It is accepted that approximately $20 \%$ of patients will not have optimal limb axis correction as measured by postoperative radiographs [20]. This can be due to imprecise preoperative planning, inaccurate wedge cuts or poor control of intraoperative alignment $[21,22]$. Another cause may be unstable fixation of the osteotomy during the bone healing process leading to secondary correction loss with revarisation or valgus overcorrection [23].

Traditional methods to assess the intraoperative mechanical axis have been crude and unreliable and this is the most common cause of over or undercorrection [10]. The cable method is most commonly used, which utilises fluoroscopy and creates a straight radio-opaque line between the centres of the hip and ankle joints to allow interpolation as to where the axis crosses the knee [24]. Other methods include using a grid with radio-opaque reference lines or the measurement of correction angles on radiographs intraoperatively $[16,25]$. These techniques have high intraobserver variation and low reproducibility and allow only momentary evaluation [26]. It is difficult to obtain long leg views intraoperatively and accuracy can also be affected by limb rotation, alignment guide position and the quality of the image intensification image [27].

Undercorrection of the frontal plane deformity leads to progression of medial joint arthritis and patient dissatisfaction [23]. Overcorrection can lead to patellar subluxation, patella baja, medial joint line opening and rapid degeneration of the lateral cartilage [28]. Another issue is that multiplanar deformity may be present and many conventional techniques fail to control for this.

Inadvertent sagittal plane realignment is a common problem after conventional open wedge HTO. An increase in the tibial slope occurs as the proximal tibia has a 3 dimensional structure with a triangular shape [10]. Noyes et al. [29] reported that the opening gap at the tibial tubercle should be approximately one half of the gap at the posteromedial tibia to maintain a normal tibial slope and that a gap error of $1 \mathrm{~mm}$ could result in a change of posterior slope of approximately 2 degrees. An increase in slope facilitates the anterior translation and subluxation of the tibia in the PCL deficient knee and can strain and damage the anterior cruciate ligament [30]. It can influence knee kinematics, stability and joint contact pressure [31].

The role of axial plane alignment after HTO is poorly understood but some authors suggest that excessive axial realignment should also be avoided [32]. Other problems with conventional HTO are that poorly performed osteotomies and incorrect orientation of the chisel or saw blade can lead to intraoperative tibial plateau fractures and injury to neurovascular structures.
It is thought that many of the difficulties outlined above can be overcome by intraoperative computer-assisted surgery or navigation procedures. Such technology has been used in other areas of orthopaedic surgery successfully, for example, total knee replacement $[33,34]$. It can allow precise evaluations of deformity and intraoperative real time control of the axes obtained by correction. It can address inadvertent technical errors in conventional surgery and improve reproducibility, allowing comparison of results. Such technology can also compensate for variations in surgeon's experiences with regard to preoperative planning. In recent years, computer navigation has been introduced to assess leg alignment intraoperatively in HTO and several groups have reported their results.

\section{Early Work}

Early attempts to improve the accuracy of HTO involved the development of preoperative planning and simulation systems which provided the surgeon with a simulation of the operation and prediction of postoperative alignment or loading [35]. Many of these systems involved two dimensional (2D) models and there were problems executing a 2D plan in 3D space [36]. A Computer Tomograph (CT)based 3D pre-surgical planner and intraoperative guidance system was then developed which aimed to increase the accuracy and reproducibility of removing a wedge for closed wedge osteotomy [37]. However this method involved an extra procedure for the insertion of radio-opaque markers into the tibia under local anaesthesia and therefore an increased risk of infection. Furthermore, after insertion of markers, a preoperative CT scan was undertaken, leading to increased radiation exposure.

\section{Current Computer Navigation Systems}

Modern day CT-free computer navigation consists of infrared camera and tracker systems. Kinematic movements and percutaneous digitisations are used to register anatomical landmarks, avoiding the use of CT. 3D graphic models of the patient's anatomy are created which are then linked to the surgery through the use of an intraoperative computer workstation. Several companies offer software to assist in HTO and these use slightly different methods to acquire the position and alignment of the limb. Orthopilot ${ }^{\mathrm{TM}}$ (B Braun Aesculap, Tuttlingen, Germany), VectorVision ${ }^{\mathrm{TM}}$ (Brainlab Inc, Heimsetten, Germany) and SurgiGATETM fluoroscopy based navigation module (Medivision, Oberdorf, Switzerland) systems have been mentioned in the literature. They can be used for both medial opening wedge and closed wedge HTO. Orthopilot ${ }^{\mathrm{TM}}$ has been cited the most and the salient features are described below. It is very similar to the Vectorvision system in that both tend to rely on preoperative radiographs to determine the amount of axis correction desirable. The SurgiGATE ${ }^{\text {TM }}$ system is a little different as it uses a fluoroscopic C-arm for intraoperative deformity measurement, planning and correction under navigational guidance [38].

\section{Orthopilot TM}

This navigation system has been used mostly with medial opening wedge HTO [39]. Using this technique, an infrared camera is set up and the patient positioned. Stab wounds are made on the distal femur and tibial shaft and navigation 
trackers are fixed by bicortical screws. A third navigation tracker is wrapped around the foot. With the newer 3D version, an additional transmitter can be fastened to the proximal third of the tibia with a $2.5 \mathrm{~mm}$ Kirschner wire to monitor the tibial slope (3D HTO navigation).

By moving the hip, knee and ankle through the range of motion for each joint, the centres of the joints are determined. Anatomical landmarks such as the femoral epicondyles and ankle malleoli are registered percutaneously with a pointer. This provides an assessment of varus deformity and the point of intersection of the mechanical axis on the tibial plateau. The amount of knee flexion and extension are also measured. The ostoeotomy is then performed in a standard incomplete open wedge manner. Valgisation by the stepwise insertion of chisels or osteotomes is performed. These are then replaced by metal spacers. The mechanical axis is visualised continuously by the navigation system. When the required correction has been achieved, the osteotomy can be stabilised with a fixation device and the spacers replaced by graft wedges. One advantage of the system is that it does not need intraoperative fluoroscopy. A disadvantage is the inability of the older version (standard version) to control sagittal plane correction or the posterior slope of the tibia [40]. There are also concerns that the kinematic pivoting algorithm for digitising the hip centre as the rotational centre of the femur around the pelvis may not work in certain situations for example if the patient has reduced range of hip movement or is obese due for example to the limited range of motion or patient obesity. Similarly, percutaneous registration of the ankle centre may not be accurate if the patient is too obese to palpate the malleoli or if there are ankle deformities. Furthermore, the system relies on preoperative imaging through full-length radiographs which can be error prone.

\section{Surgigate ${ }^{\mathrm{TM}}$}

An optoelectronic infrared tracking localiser is mounted on a movable stand and tracks the position of optical targets equipped with infrared light-emitting diodes (LEDs). These targets are attached to anatomical bodies and the image intensifier of the $\mathrm{C}$-arm as well as other relevant surgical instruments. The workstation communicates with the infrared tracking system. No preoperative planning is necessary. The following steps are undertaken:

1. Fixation of dynamic reference bases (DRBs) at the femur and tibia using kirschner wires and acquisition of fluoroscopic images with the calibrated fluoroscopic C-arm.

2. Digitisation of anatomical landmarks and measurement of functional parameters.

3. Intraoperative planning of the osteotomy plane with the aid of fluoroscopic images.

4. Navigational guidance of bone cutting and deformity correction.

The main advantages of this system are that preoperative full-length radiographs are not required. It allows continuous visualisation of the frontal, sagittal and transverse axes. It is thought that the use of fluoroscopic images is more accurate for registering the hip centre than the pivoting algorithm.

\section{Cadaveric Studies}

In cadaveric studies, computer navigation has been shown to improve accuracy. Hankemeier et al. [41] randomly assigned twenty cadaveric legs to conventional analysis of mechanical axis using the cable method or to navigated analysis with a fluoroscopy based system. CT was performed. Compared to CT analysis of the mechanical axis, navigated intraoperative evaluation was more accurate than conventional evaluation. In another paper [42], this group also demonstrated that after performing navigated or conventional HTO randomly on these cadavers, the navigated cadavers had better mechanical axis alignmnent with lower variability and reduced radiation exposure time although the operation took longer. Lützner et al. [43] also randomly assigned 19 cadaveric legs to navigated (Orthopilot ${ }^{\mathrm{TM}}$ ) or conventional open-wedge HTO and found that the mean deviation of the weight-bearing line from the desired 80 percent was 1 percent in the navigated and $8.6 \%$ in the conventional operated legs. $80 \%$ of the tibial plateau width was chosen as the desired weight-bearing line in this study as there was no varus malalignment in the cadaveric legs.

These studies although encouraging, only investigated accuracy and variability in the frontal plane. Goleski et al. [44] performed navigated HTO (VectorVision ${ }^{\mathrm{TM}}$ ) on thirteen cadaver legs and initial coronal, sagittal and axial alignment was measured on 6 legs, 3 times each at intervals. The navigation system was not good at tracking changes in tibial torsion and had poor intra and interobserver reliability in rotational alignment. Furthermore, looking at the change in tibial slope, there were sizeable differences in the navigation and CT values and only fair inter and intraobserver reliability. Despite being able to monitor simultaneous coronal, sagittal and axial alignment with navigation, it appeared that there were limits in the accuracy of determination of the sagittal and axial plane alignment.

Conversely, Yamamoto et al. [45] undertook navigated opening wedge HTO on six human cadaver knees connected with a skeleton model and examined the preoperative and postoperative CT. The study involved the use of Orthopilot $^{\mathrm{TM}} 3 \mathrm{D}$ open wedge HTO software which allows for improved intraoperative monitoring of the tibial slope and involves an additional transmitter which is fixed to the proximal tibia. The authors reported good postoperative coronal realignment as well as an insignificant change in the anatomic tibial slope but did not comment on axial plane alignment.

\section{Purpose of the Review}

To date, the results of small clinical studies have been published reporting the early experiences with navigation systems. However, there are no publications which summarise this information succinctly. The purpose of this study is to detail all the available information regarding the advances in computer-assisted high tibial osteotomy by identifying and evaluating the published literature. Through this systematic review, current pitfalls will also be discussed to direct future research.

\section{MATERIALS AND METHODOLOGY}

Studies referencing the use of navigation in High Tibial Osteotomy were searched using electronic databases 
Medline, PubMed, ZETOC, OvidSP and Cochrane library (Wiley). To identify the relevant articles, the following keywords were used; Navigated high tibial osteotomy, Computer-assisted High Tibial Osteotomy, Navigation high tibial osteotomy, Orthopilot, Surgigate, Medivision. No date limits were set. The abstracts of all hits were reviewed. Studies met the inclusion criteria if they 1) involved patients with medial unicompatmental gonarthrosis with varus deformity undergoing navigated HTO 2) were written in English 3) commented on the postoperative change in mechanical or anatomical alignment. Case reports and expert opinions were excluded and duplicates were sifted out. Suitable papers were examined and their references were also hand screened for relevant citations. A total of 47 papers were reviewed. Ten articles were identified as relevant according to the inclusion criteria.

Study characteristics such as year of publication, type of study, mean age, surgical technique, follow-up duration and outcomes were extracted by one reviewer. An electronic database was created. Outcomes of interest included correction of mechanical axis, operation duration, change of posterior tibial slope and complications associated with navigation.

\section{RESULTS}

The clinical results of navigated HTO are outlined in Table 1.

Early studies using Orthopilot ${ }^{\mathrm{TM}}$ [46] in 55 patients undergoing HTO showed good correlation between navigated measurements and those obtained from pre and postoperative radiographs. Good corrections of coronal alignment were achievable consistently with only one complication of haematoma of the distal pin track.

Also using Orthopilot ${ }^{\mathrm{TM}}$, Saragaglia and Roberts [47] compared 28 navigated open wedge HTOs with 28 conventional HTOs. The results demonstrated a $96 \%$ reproducibility in achieving a mechanical axis of $184^{\circ} \pm 2^{\circ}$ in the navigated group compared to a $71 \%$ reproducibility in achieving a mechanical axis of $184^{\circ} \pm 2^{\circ}$ in the conventional osteotomy group $(p<0.0015)$. The authors stressed that the conventional group had received stringent preoperative and perioperative planning and attention to detail. One flaw of the study was that the conventional HTOs were performed at an earlier timeframe to the navigated HTO.

Maurer and Wassmer [6] looked at 67 open wedge HTOs performed between 2003 and 2006, the first 23 of which were performed by conventional technique and the next 44 of which were performed with the Orthopilot system ${ }^{\mathrm{TM}}$. There was good correlation in the navigated group between preoperative planning and preoperative computer navigation regarding the angle of varus deformity. There was also good correlation between the navigated correction angle and postoperative measurements in another full-leg view. Navigation resulted in a statistically higher accuracy of the postoperative mechanical leg axis within a range of $3^{\circ}$ to $5^{\circ}$ valgus and fewer outliers. It extended the total operative time by only ten minutes.

A retrospective comparative study by Kim et al. [40] looked at the one year follow-up after 47 navigated and 43 conventional open wedge HTO. Similar to previous studies, the navigated group showed better results than the conventional group in both the mechanical axis and the coordinate of the weightbearing line on postoperative radiographs with better reproducibility. There was no significant difference in the complication rate in either group. Although the version of Orthopilot ${ }^{\mathrm{TM}}$ used by these authors was unable to control sagittal plane correction or posterior tibial slope, the authors took additional measures to control for this. They inserted two guide pins to overlap each other on a $10^{\circ}$ caudally tilted fluoroscope to simulate the tibial plateau view in both groups. This enabled the osteotomy to parallel the inherent slope of the tibia in the sagittal plane. Also, when adjusting the opening wedge, the authors ensured that the opening at the posteromedial corner of the tibia was about two times that at the anteromedial corner. Furthermore, in the navigated group, two different sized plates were used, the anterior plate being approximately $2 \mathrm{~mm}$ smaller than the posterior plate and in the conventional group two wedge-shaped grafts, different in height were placed into the osteotomy site to replicate the slope. There was no difference in either group between the pre or postoperative posterior slope (approx $10^{\circ}$ ). There was also no difference in the total operative time, although this was partly because autogenous bone grafts were used in the conventional group and allografts in the navigated group. The navigation group showed better results in both the mean Hospital for Special Surgery knee score and the mean Lysholm knee score. Limitations of this study included the short follow-up and the fact that different plates were used in each of the groups which may have influenced results based on their individual biomechanical properties.

Song et al. [48] performed 40 navigation-assisted open wedge HTO and followed patients up with radiographs 3 months postoperatively. They also reported good correction of mechanical axis with few outliers. Like Kim et al. they took precautions to maintain the tibial slope, for example by placing the posterior plate as posteriorly as possible and by using an anterior plate that was shorter. This group maintained the anterior gap (at the posteromedial aspect of the tibial tuberosity) at $70 \%$ of the posterior opening gap and found that the posterior slope was well maintained. There were no complications related to navigation in this study.

Iorio et al. [49] prospectively followed-up 13 patients who underwent 14 navigated open wedge HTO after a mean of 12.6 months. Like the cadaveric study performed by Yamamoto et al. [45], the authors used Orthopilot ${ }^{\mathrm{TM}} 3 \mathrm{D}$ open wedge HTO software, although only 6 patients had the additional transmitter fixed to monitor the tibial slope. Good correction of femorotibial mechanical axis was achieved overall and coronal and sagittal plane angles detected through navigation correlated well with radiograph measurements. In the six patients in whom the posterior tibial slope was evaluated, there was an insignificant change between the preoperative and postoperative values. Conversely, in patients in whom the slope was not evaluated, there was a mean increase of the slope of $2.8^{\circ} \pm 3.3^{\circ}$ seen on comparing pre and postoperative radiographs. In all patients, the HTO had no significant effect on the patella height (Insall-Salvati index) and pain and functional scores improved significantly postoperatively (Visual Analogue Score, Modified Cincinnati and Knee Society Score). There were no complications and the mean operating time was 78.9 
minutes. Again this study was limited by a small number of patients, short and variable follow-up and the lack of a control group. Akamatsu et al. [50] compared the results from 28 conventional HTO and 31 navigated HTO using the standard version of Orthopilot ${ }^{\mathrm{TM}}$. In this study, the mean postoperative femorotibial angle was higher in the conventional group, i.e. navigation reduced the risk of undercorrection in the coronal plane. By maintaining the postoperative full extension to the same degree as preoperative full extension using the navigation system, the authors found they could control the posterior tibial slope. Mean changes in posterior tibial slope before and after opening wedge HTO were $3.5^{\circ}$ in the conventional group and $0.6^{\circ}$ in the navigated group $(\mathrm{p}<0.001)$. Operations in the navigated group took on average 16 minutes longer than in the conventional group and there were no differences in functional scores or complications between the groups.

Successful outcomes have also been published using the Brainlab system for navigation. Gebhard et al. [51] undertook a prospective multicentre study case series at six centres to look at 6 week outcomes in 51 patients after open wedge HTO. The mean length of surgery was 105 minutes. $85 \%$ of patients achieved desirable mechanical axis deviations. However eight intraoperative complications occurred which were all associated with the navigation system being used during the learning phase of the study. This again highlights the steep learning curve and that experience in using the technology is fundamental in achieving good results.

Very few studies have looked at navigation using the closed wedge technique. Bae et al. [52] undertook 50 closed wedge HTO procedures using the VectorVision system and compared the results with 50 conventional closed-wedge HTO procedures undertaken during the preceding 12 years. As before, there was a positive correlation between the measurement data obtained with the navigation system and that with the radiological measurement and good inter and intraobserver reliability. The coronal correction angles were more accurate in the navigated group and the variability of correction was lower. There was also less decrease in the posterior slope angle postoperatively in the navigated group which the authors attributed to accurate orientation of the wedge and proper placement of the hinge axis under guidance. The main limitation of this study was that a prospective cohort was compared with a retrospective cohort of patients, some of whom had their operation several years beforehand. There was also some discrepancy between the demographics of the two groups.

Wang et al. [38] have experience using the Surgigate system. As this system does not rely on preoperative planning based on full leg radiograph images, which they describe as a 'manual cutting and tracing paper process', they state that it is less likely to result in under or overestimation of the correctional angle. The fluoroscopic Carm provides an intraoperative tool for deformity measurement, interactive planning and precise performance of deformity correction all at the time of surgery. This group looked at 31 patients who underwent navigated HTO at two centres. Five patients were converted to conventional HTO as there were technical problems with the navigation system. The remaining patients underwent successful correction of coronal plane deformity without complication. The extra operative time ranged from 10 to 30 minutes. The authors did not comment on whether they found any changes in sagittal or axial plane.

\section{DISCUSSION}

In this systematic review, we have looked at the clinical outcomes of using navigation systems for HTO. The studies we examined have demonstrated that the use of navigation holds some disadvantages such as the long learning curve. Technical pitfalls can occur, such as line of sight issues, registration failures and mechanical or software malfunctions [53]. Surgeons must be comfortable with the conventional osteotomy method in case such problems with the navigation system occur intraoperatively. In addition, current navigation techniques measure the mechanical axis without application of weight bearing conditions which can later account for over or undercorrections. Another disadvantage is that the additional time required for navigation ranges from 10 to 30 minutes potentially increasing the anaesthetic risk. The use of navigation entails stab wounds to the tibia and femur for fixing the trackers which can also inherently increase the risk of infection or fracture $[54,55]$ and a case of heterotopic ossification has also been described [56]. Navigation also incurs extra costs compared to the conventional technique.

Advantages of computer-assisted high tibial osteotomy are that it can substantially improve the accuracy as has been consistently seen from cadaveric and clinical studies. This can improve postoperative outcomes and decrease the radiation time. It can also provide real time intraoperative information about coronal, sagittal and transverse axes which can compensate for the shortcomings of preoperative radiograph planning. To obtain the very best results, the registration process must be precise and efforts should be taken to obtain accurate data. It is important to check for changes of the leg axis during preoperative varus and valgus stress as a leg axis discrepancy may exist between weightbearing full leg radiography and non weight-bearing navigated preoperative data. This also enables medial and lateral soft tissue status to be differentiated. Postoperative varus-valgus stress testing and observations of any axis changes during heel pushing can predict postoperative fixation stability, collateral ligament status and leg axis during full weightbearing [10].

Results concerning tibial slope control have been conflicting. Regarding Orthopilot, many of the studies above were carried out before the updated Orthopilot module was released. This does allow for tibial slope control but has been described by some as being cumbersome [10]. Regarding open wedge HTO, Song et al. have recommended the following to avoid unintended increases in the posterior slope:

1. The osteotomy should be parallel to the joint line in the sagittal plane (normal posterior slope).

2. The posterior corticotomy should be complete and posteromedial soft tissue should be released.

3. The plate should be placed as posterior as possible.

4. The postoperative full extension should be kept to the same degree as the preoperative full extension using the navigation system. 
Table 1. Clinical Studies Examining the Outcomes of Navigation in High Tibial Osteotomy

\begin{tabular}{|c|c|c|c|c|c|c|c|}
\hline Study Group & Type of Study & No of Patients & Follow-Up & $\begin{array}{l}\text { Navigation } \\
\text { System }\end{array}$ & $\begin{array}{l}\text { Internal } \\
\text { Fixation }\end{array}$ & Findings & $\begin{array}{c}\text { Complications Related } \\
\text { to Navigation }\end{array}$ \\
\hline $\begin{array}{l}\text { Wang } 2005 \\
{[38]}\end{array}$ & $\begin{array}{l}\text { Case series at two } \\
\text { centres; navigated } \\
\text { open, closed and } \\
\text { dome osteotomy }\end{array}$ & 31 & 12 weeks & Surgigate & Not stated & $\begin{array}{c}26 \text { patients treated successfully } \\
\text { with good correction of coronal } \\
\text { alignment }\end{array}$ & $\begin{array}{l}5 \text { technical problems } \\
\text { leading to conversion to } \\
\text { conventional technique }\end{array}$ \\
\hline $\begin{array}{l}\text { Saragaglia \& } \\
\text { Roberts 2005 } \\
\quad[47]\end{array}$ & $\begin{array}{l}\text { Comparative } \\
\text { study comparing } \\
\text { navigated and } \\
\text { conventional } \\
\text { OWHTO }\end{array}$ & $\begin{array}{l}56 \text { ( } 28 \text { in each } \\
\text { group) }\end{array}$ & $\begin{array}{c}\text { Post } \\
\text { operative }\end{array}$ & Orthopilot & AO T-plate & $\begin{array}{l}\text { Navigated group - better } \\
\text { correction of mechanical axis; } \\
\text { better reproducibility }\end{array}$ & No mention \\
\hline $\begin{array}{l}\text { Baur \& } \\
\text { Schuh 2006 } \\
{[46]}\end{array}$ & $\begin{array}{l}\text { Case series } \\
\text { navigated } \\
\text { OWHTO }\end{array}$ & 54 & $\begin{array}{c}\text { Post } \\
\text { operative }\end{array}$ & Orthopilot & Not stated & $\begin{array}{l}\text { Good correction of mechanical } \\
\text { axis; good reproducibility }\end{array}$ & $\begin{array}{c}\text { Haematoma of distal pin } \\
\text { track }\end{array}$ \\
\hline $\begin{array}{l}\text { Maurer } \\
\text { \&Wassmer } \\
2006[6]\end{array}$ & $\begin{array}{c}\text { Comparative } \\
\text { study - navigated } \\
\text { v conventional } \\
\text { OWHTO }\end{array}$ & $\begin{array}{c}67(23 \\
\text { navigated, } 44 \\
\text { conventional) }\end{array}$ & $\begin{array}{c}\text { Post } \\
\text { operative }\end{array}$ & Orthopilot & $\begin{array}{l}\text { Synthes } \\
\text { Tomofix }\end{array}$ & $\begin{array}{l}\text { Navigated group - better } \\
\text { correction of mechanical axis, } \\
\text { better reproducibility. Operation } \\
\text { time } 10 \text { mins longer in } \\
\text { navigated group }\end{array}$ & None \\
\hline $\begin{array}{l}\text { Song } 2007 \\
\quad[48]\end{array}$ & $\begin{array}{l}\text { Case series } \\
\text { navigated } \\
\text { OWHTO }\end{array}$ & 40 & 3 months & Orthopilot & $\begin{array}{l}\text { B Braun } \\
\text { Aesculap open } \\
\text { wedge plate }\end{array}$ & $\begin{array}{l}\text { Good correction of mechanical } \\
\text { axis, posterior tibial slope } \\
\text { maintained }\end{array}$ & None \\
\hline$\underset{[40]}{\operatorname{Kim} 2009}$ & $\begin{array}{c}\text { Comparative } \\
\text { study - navigated } \\
\text { v conventional } \\
\text { OWHTO }\end{array}$ & $\begin{array}{c}85 \text { (90 knees; } \\
43 \\
\text { conventional, } \\
47 \text { navigated) }\end{array}$ & 1 year & Orthopilot & $\begin{array}{l}\text { Taesan Sol } \\
\text { Puddu or } \\
\text { Aesculap dual } \\
\text { open wedge } \\
\text { plate }\end{array}$ & $\begin{array}{c}\text { Navigated group - better } \\
\text { correction of mechanical axis } \\
\text { and weightbearing line, better } \\
\text { functional scores. No difference } \\
\text { in tibial slope in either group. } \\
\text { No difference in operative time } \\
\text { between groups. }\end{array}$ & $\begin{array}{l}2 \text { cases of delayed union, } \\
\text { one varus collapse, all } \\
\text { associated with breakage } \\
\text { of lateral tibial cortex } \\
\text { during medial opening }\end{array}$ \\
\hline $\begin{array}{l}\text { Bae } 2009 \\
\quad[52]\end{array}$ & $\begin{array}{c}\text { Comparative } \\
\text { study navigated } \mathrm{v} \\
\text { conventional } \\
\text { CWHTO }\end{array}$ & $\begin{array}{c}82 \text { (100 knees; } \\
50 \\
\text { conventional, } \\
50 \text { navigated }\end{array}$ & $\begin{array}{c}\text { Post } \\
\text { operative }\end{array}$ & Vectorvision & $\begin{array}{l}\text { Miniplate } \\
\text { staple }\end{array}$ & $\begin{array}{c}\text { Navigated group - better } \\
\text { correction of mechanical axis } \\
\text { and better control of tibial slope. }\end{array}$ & None mentioned \\
\hline $\begin{array}{l}\text { Iorio } 2010 \\
\quad[49]\end{array}$ & $\begin{array}{l}\text { Case series } \\
\text { navigated } \\
\text { OWHTO }\end{array}$ & $\begin{array}{c}13 \text { (14 knees; } \\
\text { 3D HTO } \\
\text { navigation in } 6 \\
\text { patients) }\end{array}$ & $\begin{array}{c}5-35 \\
\text { months } \\
(\text { mean } \\
12.6)\end{array}$ & Orthopilot & $\begin{array}{c}\text { B Braun } \\
\text { Position HTO } \\
\text { plate }\end{array}$ & $\begin{array}{c}\text { Good correction of mechanical } \\
\text { axis. } \\
\text { No change in Insall-Salvati } \\
\text { index postoperatively. } \\
\text { Good functional scores } \\
\text { postoperatively. } \\
\text { Good control of tibial slope with } \\
\text { 3D navigation only. } \\
\text { Mean operative time } 78.9 \text { mins }\end{array}$ & None \\
\hline $\begin{array}{l}\text { Akamatsu } \\
2011[50]\end{array}$ & $\begin{array}{c}\text { Comparative } \\
\text { study of navigated } \\
\text { v conventional } \\
\text { OWHTO }\end{array}$ & 48 (59 knees) & 1 year & Orthopilot & $\begin{array}{l}\text { Synthes } \\
\text { Tomofix }\end{array}$ & $\begin{array}{c}\text { Navigated group - less } \\
\text { undercorrection of femorotibial } \\
\text { angle and } \\
\text { Tibial slope preserved better. } \\
\text { No difference in functional } \\
\text { scores between groups. } \\
\text { Navigated operations took } 16 \\
\text { mins longer }\end{array}$ & None \\
\hline $\begin{array}{l}\text { Gebhard } \\
2011[51]\end{array}$ & $\begin{array}{c}\text { Multicentre case } \\
\text { series of } \\
\text { navigated } \\
\text { OWHTO }\end{array}$ & 51 & 6 weeks & Vectorvision & Tomofix & $\begin{array}{l}7 \text { patients with postoperative } \\
\text { mechanical axis out of range. } \\
\text { Mean length surgery } 105 \text { mins }\end{array}$ & $\begin{array}{c}8 \text { intraoperative } \\
\text { technical complications }\end{array}$ \\
\hline
\end{tabular}

5. The anterior opening gap at the anteromedial cortex of the proximal tibia behind the tuberosity should be approximately $67 \%$ of the posterior opening gap at the most posteromedial corner of the proximal tibia [48]. Alternatively, the opening gap at the tibial tubercle should be one-half that of the opening gap at the posteromedial tibia [29].

\section{CONCLUSION}

Further research should be directed towards developing more accurate navigation tools which can monitor sagittal and axial plane alignment reliably and therefore correct multiplanar deformity. In the future, it is possible that better quantitative alignment tracking may allow osteotomy to be used successfully for patients with osteoarthritis and 
ligament instability. With this in mind, biomechanical studies are required to define ideal alignments in the coronal and sagittal planes for individualised cartilage, meniscus and ligament stability conditions. Longer follow-up studies will also be interesting to compare the long-term follow-up of navigated versus conventional HTO.

\section{ACKNOWLEDGEMENT}

None declared.

\section{CONFLICTS OF INTEREST}

Neither of the authors have a conflict of interest to declare in relation to the production of this manuscript.

\section{REFERENCES}

[1] Jackson JP. Osteotomy for osteoarthritis of the knee: proceedings of the Sheffield Regional Orthopaedic Club. J Bone Joint Surg Br 1958; 40(4): 826.

[2] Fujisawa Y, Masuhara K, Shiomi S. The effect of high tibial osteotomy on osteoarthritis of the knee. An arthroscopic study of 54 knee joints. Orthop Clin North Am 1979; 10(3): 585-608.

[3] Hernigou P, Medevielle D, Debeyre J, Goutallier D. Proximal tibial osteotomy for osteoarthritis with varus deformity. A ten to thirteenyear follow-up study. J Bone Joint Surg Am 1987; 69(3): 332-54.

[4] Insall JN, Joseph DM, Msika C. High tibial osteotomy for varus gonarthrosis. A long-term follow-up study. J Bone Joint Surg Am 1984; 66(7): 1040-8

[5] Koshino T, Wada S, Ara Y, Saito T. Regeneration of degenerated articular cartilage after high tibial valgus osteotomy for medial compartmental osteoarthritis of the knee. Knee 2003; 10(3): 22936.

[6] Maurer F, Wassmer G. High tibial osteotomy: does navigation improve results? Orthopedics 2006; 29(10 Suppl): S130-2.

[7] Koshino T, Murase T, Saito T. Medial opening-wedge high tibial osteotomy with use of porous hydroxyapatite to treat medial compartment osteoarthritis of the knee. J Bone Joint Surg Am 2003; 85-A(1): 78-85

[8] Raja Izaham RM, Abdul Kadir MR, Abdul Rashid AH, Hossain MG, Kamarul T. Finite element analysis of Puddu and Tomofix plate fixation for open wedge high tibial osteotomy. Injury 2012; 43(6): 898-902.

[9] Dorsey WO, Miller BS, Tadje JP, Bryant CR. The stability of three commercially available implants used in medial opening wedge high tibial osteotomy. J Knee Surg 2006;19(2): 95-8.

[10] Song EK, Seon JK, Park SJ, Seo HY. Navigated open wedge high tibial osteotomy. Sports Med Arthrosc 2008; 16(2): 84-90.

[11] Sprenger TR, Doerzbacher JF. Tibial osteotomy for the treatment of varus gonarthrosis. Survival and failure analysis to twenty-two years. J Bone Joint Surg Am 2003; 85-A(3): 469-74.

[12] Pfahler M, Lutz C, Anetzberger H, et al. Long-term results of high tibial osteotomy for medial osteoarthritis of the knee. Acta Chir Belg 2003; 103(6): 603-6.

[13] Coventry MB. Osteotomy of the upper portion of the tibia for degenerative arthritis of the knee. A preliminary report. J Bone Joint Surg Am 1965; 47: 984-90.

[14] Koshino T, Yoshida T, Ara Y, Saito I, Saito T. Fifteen to twentyeight years' follow-up results of high tibial valgus osteotomy for osteoarthritic knee. Knee 2004; 11(6): 439-44.

[15] Ivarsson I, Myrnerts R, Gillquist J. High tibial osteotomy for medial osteoarthritis of the knee. A 5 to 7 and 11 year follow-up. J Bone Joint Surg Br 1990; 72(2): 238-44.

[16] Paley D, Herzenberg JE, Eds. Principles of deformity correction. Berlin; London: Springer 2002.

[17] Miniaci A, Ballmer FT, Ballmer PM, Jakob RP. Proximal tibial osteotomy. A new fixation device. Clin Orthop Relat Res 1989; (246): 250-9.

[18] Noyes FR, Barber SD, Simon R. High tibial osteotomy and ligament reconstruction in varus angulated, anterior cruciate ligament-deficient knees. A two- to seven-year follow-up study. Am J Sports Med 1993; 21(1): 2-12.

[19] Jakob RP, Murphy SB. Tibial osteotomy for varus gonarthrosis: indication, planning, and operative technique. Instr Course Lect 1992; 41: 87-93.
[20] Jenny JY, Tavan A, Jenny G, Kehr P. Long-term survival rate of tibial osteotomies for valgus gonarthrosis. Rev Chir Orthop Reparatrice Appar Mot 1998; 84(4): 350-7.

[21] Dahl MT. Preoperative planning in deformity correction and limb lengthening surgery. Instr Course Lect 2000; 49: 503-9.

[22] Pearle AD, Goleski P, Musahl V, Kendoff D. Reliability of imagefree navigation to monitor lower-limb alignment. J Bone Joint Surg Am 2009; 91(Suppl 1): 90-4.

[23] Lobenhoffer P, Van Heerwaarden R, Staubli A, Jakob R. Osteotomies around the knee : indications, planning, surgical techniques using plate fixators. Stuttgart: Thieme 2008.

[24] Krettek C, Miclau T, Grun O, Schandelmaier P, Tscherne H. Intraoperative control of axes, rotation and length in femoral and tibial fractures. Technical note. Injury 1998; 29(Suppl 3): C29-39.

[25] Saleh M, Harriman P, Edwards DJ. A radiological method for producing precise limb alignment. J Bone Joint Surg Br 1991; 73(3): 515-6

[26] Hankemeier S, Gosling T, Richter M, Hufner T, Hochhausen C, Krettek C. Computer-assisted analysis of lower limb geometry: higher intraobserver reliability compared to conventional method. Comput Aided Surg 2006;11(2): 81-6.

[27] Kawakami H, Sugano N, Yonenobu K, et al. Effects of rotation on measurement of lower limb alignment for knee osteotomy. J Orthop Res 2004; 22(6): 1248-53.

[28] Sim JA, Kwak JH, Yang SH, Choi ES, Lee BK. Effect of weightbearing on the alignment after open wedge high tibial osteotomy. Knee Surg Sports Traumatol Arthrosc 2010; 18(7): 874-8.

[29] Noyes FR, Goebel SX, West J. Opening wedge tibial osteotomy: the 3-triangle method to correct axial alignment and tibial slope. Am J Sports Med 2005; 33(3): 378-87.

[30] Giffin JR, Stabile KJ, Zantop T, Vogrin TM, Woo SL, Harner CD. Importance of tibial slope for stability of the posterior cruciate ligament deficient knee. Am J Sports Med 2007; 35(9): 1443-9.

[31] Giffin JR, Vogrin TM, Zantop T, Woo SL, Harner CD. Effects of increasing tibial slope on the biomechanics of the knee. Am J Sports Med 2004; 32(2): 376-82.

[32] Kendoff D, Lo D, Goleski P, Warkentine B, O'Loughlin PF, Pearle AD. Open wedge tibial osteotomies influence on axial rotation and tibial slope. Knee Surg Sports Traumatol Arthrosc 2008; 16 (10): 904-10.

[33] Decking R, Markmann Y, Fuchs J, Puhl W, Scharf HP. Leg axis after computer-navigated total knee arthroplasty: a prospective randomized trial comparing computer-navigated and manual implantation. J Arthroplasty 2005; 20(3): 282-8.

[34] Victor J, Hoste D. Image-based computer-assisted total knee arthroplasty leads to lower variability in coronal alignment. Clin Orthop Relat Res 2004; (428): 131-9.

[35] Keppler P, Gebhard F, Grutzner PA, et al. Computer aided high tibial open wedge osteotomy. Injury 2004; 35(Suppl 1): S-A68-78.

[36] Chao EY, Sim FH. Computer-aided preoperative planning in knee osteotomy. Iowa Orthop J 1995; 15: 4-18.

[37] Ellis RE, Tso CY, Rudan JF, Harrison MM. A surgical planning and guidance system for high tibial osteotomy. Comput Aided Surg 1999; 4(5): 264-74.

[38] Wang G, Zheng G, Gruetzner PA, et al. A fluoroscopy-based surgical navigation system for high tibial osteotomy. Technol Health Care 2005; 13(6): 469-83.

[39] B Braun Orthopilot Navigation System. Available from: www. orthopilot.com [Accessed: $8^{\text {th }}$ Feb 2012].

[40] Kim SJ, Koh YG, Chun YM, Kim YC, Park YS, Sung CH. Medial opening wedge high-tibial osteotomy using a kinematic navigation system versus a conventional method: a 1-year retrospective, comparative study. Knee Surg Sports Traumatol Arthrosc 2009; 17(2): 128-34.

[41] Hankemeier S, Hufner T, Wang G, et al. Navigated intraoperative analysis of lower limb alignment. Arch Orthop Trauma Surg 2005; 125(8): 531-5.

[42] Hankemeier S, Hufner T, Wang G, et al. Navigated open-wedge high tibial osteotomy: advantages and disadvantages compared to the conventional technique in a cadaver study. Knee Surg Sports Traumatol Arthrosc 2006; 14(10): 917-21.

[43] Lutzner J, Gross AF, Gunther KP, Kirschner S. Precision of navigated and conventional open-wedge high tibial osteotomy in a cadaver study. Eur J Med Res 2010; 15(3): 117-20. 
[44] Goleski P, Warkentine B, Lo D, Gyuricza C, Kendoff D, Pearle AD. Reliability of navigated lower limb alignment in high tibial osteotomies. Am J Sports Med 2008; 36(11): 2179-86.

[45] Yamamoto Y, Ishibashi Y, Tsuda E, Tsukada H, Kimura Y, Toh S. Validation of computer-assisted open-wedge high tibial osteotomy using three-dimensional navigation. Orthopedics 2008; 31 (10 Suppl 1).

[46] Baur W, Schuh A. CT-free computer navigated high tibial osteotomy (HTO) in medial osteoarthritis of the knee. J Bone Joint Surg Br 2006; 88B (Suppl): 91.

[47] Saragaglia D, Roberts J. Navigated osteotomies around the knee in 170 patients with osteoarthritis secondary to genu varum. Orthopedics 2005; 28(10 Suppl): s1269-74.

[48] Song EK, Seon JK, Park SJ. How to avoid unintended increase of posterior slope in navigation-assisted open-wedge high tibial osteotomy. Orthopedics 2007; 30(10 Suppl): S127-31.

[49] Iorio R, Vadala A, Giannetti S, et al. Computer-assisted high tibial osteotomy: preliminary results. Orthopedics 2010; 33(10 Suppl): 82-6.

[50] Akamatsu Y, Mitsugi N, Mochida Y, et al. Navigated opening wedge high tibial osteotomy improves intraoperative correction angle compared with conventional method. Knee Surg Sports Traumatol Arthrosc 2012; 20(3): 586-93.

[51] Gebhard F, Krettek C, Hufner T, et al. Reliability of computerassisted surgery as an intraoperative ruler in navigated high tibial osteotomy. Arch Orthop Trauma Surg 2011; 131(3): 297-302.

[52] Bae DK, Song SJ, Yoon KH. Closed-wedge high tibial osteotomy using computer-assisted surgery compared to the conventional technique. J Bone Joint Surg Br 2009; 91(9): 1164-71.

[53] Kendoff D, Citak M, Pearle A, et al. Influence of lower limb rotation in navigated alignment analysis: implications for high tibial osteotomies. Knee Surg Sports Traumatol Arthrosc 2007; 15(8): 1003-8.

[54] Ossendorf C, Fuchs B, Koch P. Femoral stress fracture after computer navigated total knee arthroplasty. Knee 2006;13(5): 3979.

[55] Sikorski JM, Blythe MC. Learning the vagaries of computerassisted total knee replacement. J Bone Joint Surg Br 2005;87(7): 903-10.

[56] Citak M, Kendoff D, O'Loughlin PF, Pearle AD. Heterotopic ossification post navigated high tibial osteotomy. Knee Surg Sports Traumatol Arthrosc 2009; 17(4): 352-5. 